\title{
AULA: HISTÓRIA DA ARQUEOLOGIA NO BRASIL
}

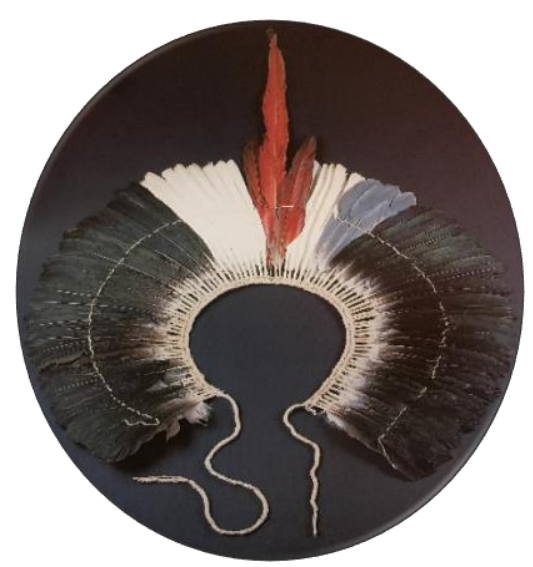

Patricia Bayod Donatti

RESUMO: Esse artigo traz algumas reflexões sobre a História da Arqueologia em diversos contextos. Em uma visão geral, as ideias de Trigger são utilizadas por inúmeros arqueólogos. Algumas dessas ideias são analisadas por DíazAndreu na América Latina através de seu interesse pelo desenvolvimento da história do nacionalismo e arqueologia, além de tópicos mais atuais como identidade e gênero. Na América do Sul, em 1997, os arqueólogos contextualizaram o desenvolvimento regional da disciplina e a conexão entre os pesquisadores da região. A interferência dos aspectos sociais e políticos são discutidos por Politis \& Perette, Acuto \& Zarankin que esboçaram um terreno positivo para o futuro da arqueologia da América do Sul. O campo da História da Arqueologia no Brasil é ainda representado por poucos pesquisadores como Barreto, Carvalho \& Funari, Ferreira, Funari, Reis. Suas pesquisas exploram temas como os contextos sócio-políticos da arqueologia no Brasil, a institucionalização da disciplina, o desenvolvimento teórico e metodológico da arqueologia brasileira.

PALAVRAS-CHAVE: Arqueologia. História. Brasil.

\section{A HISTÓRIA DA ARQUEOLOGIA NO CONTEXTO MUNDIAL}

1 UNICAMP/NEPAM/LAP-Laboratório de Arqueologia Pública Paulo Duarte/Unicamp 
Por que é importante estudar criticamente a História da Arqueologia? Como assinala Bruce Trigger (1989, 2006), examinar os processos de desenvolvimento do pensamento arqueológico através do tempo permite-nos entender como os contextos históricos, políticos, sociais e ideológicos fundamentam cada escola teórica do pensamento arqueológico. Sem dúvida, as propostas de Trigger têm sido uma das maiores influênciascomo cita Barreto (1999), Funari (2000), Ferreira (2010), Reis (2004) - para que diversos colegas se interessassem pela temática. Referindo-se a Collingwood, Trigger pontua que interpretação arqueológica e história da arqueologia estão alinhadas (TRIGGER, 2006).

Trigger $(1989,2006)$ discorreu sobre todo o processo de construção da disciplina, mostrando os elos existentes entre a produção do conhecimento sobre o passado e sociedade, a partir de uma perspectiva histórica. Ele pesquisou como foi pensado o fazer arqueológico ao longo do tempo desde o Antiquarismo até o final da década de 90.

Dentro do desenvolvimento da arqueologia atual, Trigger examinou que Nova Arqueologia que se iniciou em 1960/1970 tinha como sustentação, primeiramente a crítica a Arqueologia Histórico-Cultural que tinha foco em organizar unidades culturais e não se interessava em explicar mudança cultural, mas simplesmente em mostrar essas diferenças através do tempo/espaço. Assim, a Nova Arqueologia foi uma reação a arqueologia tradicional descritiva que simplesmente acumulava e descrevia o material arqueológico. A proposta da Nova Arqueologia - comumente ligada a Lewis Roberts Binford e seus discípulos - era a pesquisa de problemas orientados, com teste de hipóteses através de métodos científicos que resultavam em deduções generalizadas. (TRIGGER, 1989, 2006)

Em seguida, a corrente teórica pós-processualista, associada ao arqueólogo Ian Hodder, foi uma resposta a abordagem científica da Nova Arqueologia. Os pós-processualistas criticaram as generalizações da cultura 
e do registro arqueológico e enfatizaram a importância de se analisar o contexto, significado, identidade, multivocalidade e gênero (TRIGGER, 1989, 2006).

A partir da história desses debates, Trigger examina a extensão das teorias arqueológicas e a relação entre a interpretação arqueológica e o contexto social do arqueólogo. Por exemplo, um dos desdobramentos da corrente pós-processualista, reforçaria a ideia de que a multivocalidade na arqueologia é uma forma empoderamento para grupos subalternos (TRIGGER, 2006).

Em um de seus artigos seminais, Trigger propôs três tipos ideais de arqueologias alternativas: nacionalista, colonialista e imperialista, considerando uma visão coerente da arqueologia e uma variabilidade de arqueologias produzidas em diferentes contextos e períodos históricos (TRIGGER, 1984: 355-356). Para ele, existe uma relação muito próxima entre a natureza da pesquisa arqueológica e o seu meio social na qual ela é praticada; sugerindo que a pesquisa arqueológica é moldada de acordo com regras econômicas, políticas e culturais de nações específicas, como parte interdependente do sistema social moderno (TRIGGER, 1984: 336 apud WALLERSTEIN, 1974: 3-11).

Assim, a arqueologia colonialista foi desenvolvida em países onde populações nativas foram tomadas por europeus ou onde os europeus continuaram dominando política e economicamente essas populações por um longo período de tempo (TRIGGER, 1984: 361). É uma arqueologia produzida por pessoas que não tem relação histórica com os povos anteriores que elas estudam e que enfatizam a primitividade dos nativos e sua incapacidade de inovação (TRIGGER, 1984: 361). Os exemplos de Trigger vinculam a arqueologia com a antropologia nos Estados Unidos e na Austrália, associando o estereótipo de que povos nativos são tribos estáticas, atrasadas, ou aos aborígenes que nunca mudam (TRIGGER, 1984: 361). Os arqueólogos colonialistas acabam por difamar a imagem dos nativos para 
justificar o controle sobre o país dominado (TRIGGER, 1984: 362). Essa arqueologia é produzida em quase toda a América Latina (TRIGGER, 1984: 368).

A arqueologia imperialista está associada a um pequeno número de países que exercem domínio político sobre grandes áreas do mundo (TRIGGER, 1984: 363). Esses países hegemônicos possuem poder cultural, político e econômico e influenciam nações vizinhas (TRIGGER, 1984: 363). Um exemplo de arqueologia imperialista é a arqueologia americana DO pósguerra, com início em 1960. Denominada de Nova Arqueologia, teve como principal foco usar dados arqueológicos para estabelecer generalizações universais sobre comportamento humano (TRIGGER, 1984: 366). Para Trigger, a Nova Arqueologia não tem a intenção de entender a pré-história, pelo contrário, ela se nega a entender a validade da pré-história de específicas partes do mundo, confirmando a irrelevância das tradições nacionais e de qualquer assunto que esteja no caminho de influência política e de atividades econômicas americanas (TRIGGER, 1984: 366)

Para a arqueologia nacionalista, ele cita o exemplo da arqueologia produzida por arqueólogos do século XIX e início do XX, como Gustav Kossinna, que tentou provar que a Alemanha seria o berço dos povos indoeuropeus e o centro de criatividade cultural dos tempos pré-históricos, enaltecendo a pureza e a superioridade racial alemã (TRIGGER, 1984: 360), visão que foi utilizada pelos nazistas.

O México após a Revolução de 1910 é outro exemplo de uma arqueologia nacionalista criada quando as reformas econômicas e sociais prometidas pela Revolução foram substituídas pelo enobrecimento das civilizações pré-hispânicas, cuja maioria da população era composta por nativos, pela unificação nacional e por um referencial de importância cultural do passado para o mundo através da criação de sítios a céu aberto, museus de entretenimento e turismo (TRIGGER, 1984:359). 
Para entender, portanto, qual arqueologia está se desenvolvendo ou se desenvolveu em determinado lugar e tempo é necessário saber quais as perguntas e quais as pesquisas os arqueólogos (as) estão fazendo, com a finalidade de perceber esses indivíduos dentro de um contexto social e de grupos políticos (TRIGGER, 1984: 369). Segundo Trigger, atingir esse nível de compreensão seria o ponto de partida e a síntese da pesquisa (TRIGGER, 1984: 369).

\section{A HISTÓRIA DA ARQUEOLOGIA NO O CONTEXTO LATINO-AMERICANO}

Essas questões propostas por Trigger são feitas por Díaz Andreu ao discutir como as identidades atuais, como a nacionalista influenciam a forma como pensamos sobre o passado (DÍAZ-ANDREU, 2001).

Ao examinar o papel do nacionalismo na arqueologia, ela mostrou a importância de entendermos o conceito de nação e suas transformações ao longo tempo em conjunto as questões conjunturais onde as identidades contemporâneas moldam a forma de interpretar o passado (DIAZ ANDREU, 2001). Mais ainda, ela ressalta que essa interconexão profunda entre ideologia política e arqueologia precisa ser reconhecida por profissionais da área com a finalidade de compreender e contextualizar nosso trabalho (DÍAZ-ANDREU \& CHAMPION, 2015: 3).

Ao desenvolver seu texto, a autora parte de que o passado sempre teve um valor (DÍAZ ANDREU, 2001). Desde o Renascimento, as elites buscavam as antiguidades como metáforas de sua riqueza e do seu poder. Esse passado manteve seu valor dentro de uma arqueologia erudita que se torna profissional no final do século XVIII, devido ao nacionalismo do Estado moderno (DÍAZ-ANDREU, 2001). A partir do final do século XIX, as revoluções de independência de alguns países como França e Holanda na Europa e dos Estados Unidos, bem como as revoluções de independência no início do século XX da América Latina fizeram que as classes médias 
entrassem em conflito com os governantes, retirando-lhes a autoridade, e vindo à tona uma ideia de nação (DÍAZ-ANDREU, 2001). Mesmo com suas transformações ao longo do tempo, o nacionalismo mantém sua importância na análise dos desenvolvimentos atuais da arqueologia mundial, por exemplo, na inclusão dos excluídos. Um caso é o dos povos nativos que surge para legitimar seus direitos dentro de um mundo globalizado. Atualmente, Díaz Andreu \& Champion (2015) trabalham com a temática arqueologiacomunidade e valor social, onde levantam questões como: O que fazer quando as comunidades não querem ser indagadas sobre seu passado? Temos que obrigar a comunidade a lembrar de uma parte de seu passado? Nós, arqueólogos, devemos ter a última palavra sobre o passado daquela comunidade? E, finalmente, por que estamos hoje fazendo essa Arqueologia? (DÍAZ-ANDREU \& CHAMPION, 2015)

Devemos incluir ainda dentro da discussão sobre identidades, o gênero que foi incluído na arqueologia somente a partir de 1980. (DÍAZANDREU 2014). Em História del studio del gênero em Arqueología a autora conclui que é necessário entender o papel do arqueólogo na sociedade ao olhar de maneira crítica a masculinidade (DIAZ-ANDREU, 2014).

\section{A HISTÓRIA DA ARQUEOLOGIA NO CONTEXTO SUL AMERICANO}

Segundo Politis \& Peretti (2004), não houve uma arqueológica teórica nem conceitual na América do Sul porque consumimos teorias como a Histórico-cultural, a Nova Arqueologia e o Pós-Processualismo de países anglo-saxões, ou então, adaptamos essas teorias. No entanto, segundo esses pesquisadores esse quadro vem mudando com o aumento de trabalhos reflexivos de pesquisadores nessa região que tem interesse na construção de teorias para a América do Sul.

Essas mudanças ocorreram devido ao contexto político e o processo de democratização que vinha tomando espaço desde 1980 deixando 
para trás a desestabilização política, o fim das lutas armadas internas e da ditadura (POLITIS \& PERET'TI, 2004; ACUTO \& ZARANKIN, 2008).

A partir do ano de 1997 houve um encontro entre arqueólogos para impulsionar o diálogo na América Latina com a finalidade de encontrar novas perspectivas para a arqueologia sul-americana. Houve um aumento do contato de arqueólogos da região

Dentro dessa conjuntura foi criado o TAAS e foram estimuladas novas publicações. Por exemplo Haber e Gnecco (2007) introduziram no quarto volume da revista Arqueologia Sul-Americana uma diversidade de artigos de pesquisadores do Brasil, Peru e Colômbia que compõem uma obra de análise teoricamente fundamentada e crítica sobre diferentes temáticas da arqueologia sul-americana Além disso, nesses encontros foram geradas novas formas de abordar o passado, como o interesse nas interações e práticas sociais, na construção, negociação e difusão de significados, nas experiências subjetivas, nas relações de poder, nas relações de gênero e agencia (ACUTO \& ZARANKIN, 2008).

Essa arqueologia transformadora focava sobre o papel dos arqueólogos, seu contexto social, a importância que a cultura material e a espacialidade têm na vida social, nas relações sociais, na forma de se fazer trabalhos de campo e nas narrativas arqueológicas produzidas (ACUTO \& ZARANKIN, 2008).

Para Acuto \& Zarankin (2008), a relevância da "arqueologia pública" difundida por Funari (2001) fez com os pesquisadores tivessem um posicionamento político e ético, além de promover a inclusão das vozes e dos saberes dos subalternos, difundindo o conhecimento arqueológico fora do campo acadêmico. 


\section{OS ESTUDOS DENTRO DA HISTÓRIA DA ARQUEOLOGIA NO BRASIL}

Segundo Funari (1999), a arqueologia como ciência acadêmica não está livre de suas ligações sociais e políticas e os arqueólogos trabalham pressionados por indagações de sua sociedade e época.

Em uma análise temporal ampla sobre o tema, Funari (1994) fez um exame da arqueologia desde o Império até os dias, se posicionando dentro da História Social da Arqueologia. Assim como Funari (1994, 1999), Ferreira (2010), em seu livro Território Primitivo. Nesse livro, o autor (Ferreira, 2010) tratou da institucionalização da Arqueologia no Brasil entre 1870 a 1917 através do estudo sobre a arqueologia e colonialismo e arqueologia e nacionalismo. Utilizando-se de um recorte histórico entre 1870 a 1917, desenvolveu uma pesquisa sobre a institucionalização da Arqueologia no Brasil. Através da pesquisa sobre o Museu Paulista, Museu Botânico, Museu Goeldi, Museu Paraense, além do IGHB e o Museu Nacional. Ferreira mostrou o Museu Botânico como representante do Império e o Museu Paulista e Museu Paraense como representantes da ciência do governo republicano (FERREIRA, 2010: 22). Para ele, a arqueologia do Império, nobiliárquica, se pautava em mitos e referia-se aos objetos arqueológicos como relacionados aos fenícios, egípcios e gregos; vestindo os indígenas enterrados como nobres (Ferreira, 2010: 59). Por outro lado, a arqueologia produzida por Ihering, diretor do Museu Paulista estava relacionada a uma mundialização da arqueologia onde os modelos já estavam prontos para serem praticados com propósitos coloniais. (FERREIRA, 2010). Assim, a criação de fronteiras nacionais estava sendo estabelecida junto a uma arqueologia nacionalista (FERREIRA, 2010). Segundo o autor, "as narrativas bistórico-nacionalistas formaram-se a partir de uma atitude expansionista, acicatadas pelo avanço em territórios e pela negação da alteridade do Outro" (Ferreira, 2010: 58). A arqueologia, portanto, institucionalizou-se vocalizando identidades nacionais ao fornecer matéria-prima para elaboração de símbolos nacionais, 
naturalizando dessa forma, o sentimento de pertencimento a nação (Ferreira, 2010: 22). Sobre os financiamentos dessas pesquisas, Funari (1999) discorre que a arqueologia do século XIX foi feita por estudiosos ligados ao Museu Nacional do Rio de Janeiro, Museu Histórico Nacional, Museu Paulista sendo os trabalhos de campo e laboratório coordenados pelos seus diretores que conseguiam o patrocínio da elite (FUNARI, 1999). Assim, a arqueologia brasileira só se iniciaria de fato, com propósitos de pesquisa e educacionais a partir da Segunda Guerra Mundial. (FUNARI, 2000)

\section{ARQUEOLOGIA E POLÍTICA}

Segundo Funari (1999), Funari \& Carvalho (2012), o início da arqueologia acadêmica está ligado ao humanista Paulo Duarte na Universidade de São Paulo quando retornou do exílio que estava por oposição ao Estado Novo. No entanto, seus ideais de ética a proteção de patrimônio e desenvolvimento de instituições acadêmicas entraram em choque com os nepotistas e com as relações de clientelismo. Funari (1999) e Funari \& Carvalho (2012) se basearam na documentação de Paulo Duarte para analisar a luta política desse arqueólogo na institucionalização da Arqueologia na Universidade de São Paulo durante o regime militar (FUNARI, 2000; FUNARI \& CARVALHO, 2012).

Logo após golpe, firmou-se um acordo entre a United States Agency for Inter-American Development e o Ministério da Educação e Cultura do Brasil com o intuito de organizar a educação nacional a partir de uma ideologia de segurança nacional que se desdobrava no interesse em unificar ideologicamente o Ocidente (FUNARI, 1999). Esta abordagem positivista tinha por detrás arqueólogos americanos ligados ao establishment americano e aos militares sul-americanos (FUNARI, 1999: 214).

Ligados a essa ideologia, a arqueologia brasileira foi construída por arqueólogos do PRONAPA (Programa Nacional de Pesquisas 
Arqueológicas), sob a coordenação de Betty Meggers e Clifford Evans que disseminaram sua metodologia pelo Brasil (FUNARI 2000, BARRETO 1999, 2000). Utilizando-se de uma ideologia nacionalista promovida pelo autoritarismo do regime militar, o PRONAPA trabalhou em conjunto com os propósitos do Estado (FUNARI, 2000, FUNARI \& CARVALHO 2012). Funari \& Carvalho (2012) ainda enfatizam que precisamos admitir que as influências internas e externas da arqueologia que fazemos ainda guardam prejuízos sociais, afetando diretamente a pesquisa como ocorreu no passado. Por exemplo, há ainda uma dificuldade em pesquisar criticamente alguns estudiosos como Curt Nimuendajú que legitimou os ideais nacionalistas e androcêntricos na sociedade através da pacificação, das etnografias e do colecionismo (DONATTI, 2013, 2016).

\section{AS DISCUSSÕES SOBRE TEORIA E MÉTODO}

Inicialmente, houve uma falta de interesse dos arqueólogos brasileiros em absorver a influência dos historiadores marxistas ingleses e da École des Annales difundidas no Brasil, bem como o distanciamento da tradição marxista que existia no Brasil e na América do Sul (BARRETO, 2000).

Segundo a autora (BARRETO 2000), a arqueologia brasileira não teve embasamento teórico-metodológico para entender os sítios arqueológicos das sociedades nativas (BARRETO, 1999, 2000). No entanto, ela aponta a importância das metodologias de campo e laboratório que foram inseridas nas instituições brasileiras através da dos métodos de campo e classificatórios de Joseph e Anette Emperarie e das Missões Francesas, que traziam os ensinamentos de Leroi-Gourhan (BARRETO, 2000). No entanto, as escavações demoradas por métodos de decapagem não eram atraentes para os acadêmicos. Além dos métodos, a forma independente com que as 
missões francesas atuaram no Brasil fez com que não houvesse um debate teórico de arqueólogos em termos nacionais.

Posteriormente, Betty Meggers e Clifford Evans aplicaram seus métodos de escavação e seriação em categorias de fase, subfase, tradição que foram inseridos nos laboratórios. O PRONAPA (1965-1970), coordenado por esses arqueólogos, tinha o objetivo de mapear os sítios arqueológicos. $\mathrm{Na}$ Amazônia, através do PRONAPABA, Meggers inseriu o neoevolucionismo americano e a ecologia cultural de 1950, mas pouco dessas teorias foram passadas a seus orientandos (BARRETO, 2000). Para a autora, o legado de pesquisadores estrangeiros e das missões francesas nem sempre deram conta de explicar os sítios arqueológicos brasileiros e devem ser vistos dentro do contexto da comunidade acadêmica (BARRETO 2000).

Interessado, assim como Barreto (1999, 2000) no desenvolvimento teórico-metodológico da arqueologia brasileira, Reis (2004) examinou a presença de teoria ou não nas pesquisas arqueológicas brasileiras entre 1970 a 2001. Utilizando-se de um extenso levantamento bibliográfico concluiu que todos esses trabalhos empíricos possuíam alguma abordagem teórica que estaria explícita ou implícita no texto (REIS 2004). A posição teórica mais utilizada foi a Nova Arqueologia, seguida da Arqueologia Pós-Processual, Escola Francesa e Histórico-Cultural. Os autores mais citados dentro dessas correntes foram Binford, Hodder, Leroi-Gourhan e Meggers. Funari, ligado a uma posição pós-processualista, foi o mais citado entre os arqueólogos brasileiros (REIS, 2004)

\section{CONCLUSÃO}

Até o momento, existem poucas pesquisas sobre a História da arqueologia no Brasil. Barreto (1999, 2000, 2012), Ferreira (2010), Funari (1999, 2000), Funari \& Carvalho (2012) Funari \& Ferreira (2006) e Reis (2004) têm aberto caminhos para novas pesquisas. 
O recorte histórico feito por Ferreira (2010) sobre a institucionalização da arqueologia brasileira entre 1870 a 1917, analisando tópicos chaves da arqueologia como colonialismo e nacionalismo bem como as relevantes pesquisas de Funari (1994, 2000), Funari \& Carvalho (2012) sobre a luta de Paulo Duarte para a inserção na disciplina na Universidade de São Paulo durante o regime militar orientam os arqueólogos a pesquisarem a história da arqueologia e da sua teoria, como fizeram Barreto $(1999,2000)$ e Reis (2004). Essa orientação implica na consciência do arqueólogo em construir uma arqueologia crítica.

*** Agradecimentos: Aos Professores Andrés Zarankin pelas sugestões de leitura e Pedro Paulo Funari pela amizade e por dividir todo seu conhecimento.

\section{REFERÊNCIAS}

ACUTO, F \& ZARANKIN, A. 2008 Introducción. In: Acuto, Felix; Zarankin, Andrés (comp.). Sed non satiata II. Córdoba: Encuentro Grupo Editor, pp. 9-34.

BARRETO, C. 1999 Arqueologia Brasileira: uma perspectiva histórica e comparada. Revista do Museu de Arqueologia e Etnologia, 7:201-212.

BARRETO, C. 2000 A construção de um passado pré-colonial: uma breve história da arqueologia no Brasil. Revista USP, São Paulo, 44: 35-51.

BARRETO, C. 2012 Em nome da descolonização da arqueologia brasileira. Resenha do livro Território Primitivo. Revista de Arqueologia (Sociedade de Arqueologia Brasileira), 24 :124-131.

DÍAZ-ANDREU, M. 2001 Nacionalismo y Arqueologia: el contexto político de nuestra disciplina. Revista do Museu de Arqueologia e Etnologia, São Paulo, 11: 3-20.

DÍAZ-ANDREU, M. 2014 Historia del studio del género em Arqueologìa. In Vizcaíno, A. et al . (eds.), Desmutant Lara Croft Dones, arqueologia i universitat. Saguntum. Extra 15. València, Universitat de València: 25-32.

DÍAZ-ANDREU, M. \& CHAMPION, T. 2015 Nationalism and Archaeology in Europe. New York, Routledge.314 pp.

DONATTI, P.B. 2013 As Políticas da Antropologia Brasileira: o caso de Curt Nimuendajú. Curitiba: Appris. 336 pp. 
DONATTI, P.B. 2016 Resquícios de Curt Nimuendajú. Revista de Arqueologia Pública, v.10, p.81-90

FERREIRA, L.M. 2010 Território Primitivo: A Institucionalização da Arqueologia no Brasil (1870-1917). Porto Alegre: ediPUCRS.220 pp.

FUNARI, P.P. A. 1994. Arqueologia Brasileira: visão geral e reavaliação. Revista de História da Arte e Arqueologia. Unicamp, campinas, 1, 23-41.

FUNARI, P.P. A. 2000 Como se tornar arqueólogo no Brasil. Revista USP, São Paulo, 44: 74-85.

FUNARI, P.P.A. 2001 Public Archaeology from a Latin America Perspective. Public Archaeology, 1: 239-243.

FUNARI, P.P.A. \& CARVALHO, A. V. 2012 Universidades, Arqueologia e Paulo Duarte. Revista do Museu de Arqueologia e Etnologia. São Paulo: Universidade de São Paulo, 22: 89-96.

FUNARI, P.P.A. \& FERREIRA, L. M. 2006 A Social History of Brazilian Archaeology: A Case Study. Bulletin of History of Archaeology, 16: 18-27.

HABER, A. \& GNECCO, C. 2007 Editorial. Arqueología Suramericana/Arqueologia Sul-Americana. V 3, N 1, p. 2.

POLITIS, G \& PERETTI, R. D. 2004 Teoría Arqueologica en America Del Sur. Olavarría: INCUAPA/UNICEN.

REIS, J.A. 2004 Não pensa muito que dói - um palimpsesto sobre teoria na arqueologia brasileira. Tese de doutorado. Campinas, Unicamp. 383 pp.

TRIGGER, B.1984 Alternative Archaelogies: Nacionalist, Colonialist, Imperialist Man, 19: 355-370.

TRIGGER, B. 1989. A History of Archaeological Thought. Cambridge, Cambridge University Press.500 pp.

TRIGGER, B. 2006 A History of Archaeological Thought (Second Edition). Cambridge, Cambridge University Press. 710 pp.

WALLERSTEIN, I. 1974 The modern world-system, I. New York: Academic Press.409 pp. 